\title{
BUDAYA PINDAPATA: DINAMIKA INTERAKSI SOSIAL BHIKKHU SANGHA DENGAN UMAT AWAM
}

\author{
Sugianto \\ STABN Sriwijaya \\ sugiantovijjayasena@gmail.com
}

\begin{abstract}
The Monk Sangha and lay people are two Buddhist community groups who need each other. The interwoven social interaction between these two groups, one of which occurred in the activity of Pindapata. In the beginning the monks performed pindapata sangha to meet food needs. But on the next, performed with a variety of pindapata intents and purposes. The outline of this research is the issue on how the dynamics of social interaction monk sangha with the laymen of the sangha when pindapata? This research aims to clarify the dynamics of social interaction monk sangha with the laymen of the sangha when pindapata. This research is a descriptive qualitative research. The object of the research is pindapata and social interaction. The subject of this research is the monk, romo, laymen. The research was carried out in Jakarta and Tangerang in March until June 2016. Data collection techniques with triangulation through observation, interviews, and documentation. Test the validity of the data with a test of credibility, dependability, confirm ability and transferability of research results. Data analysis was done using model of Miles and Huberman. The results of this research are the Buddhist culture is pindapata in the form of abstracts, social activities and material. Social interaction is aiming to meet the basic necessities of monks and charity program. Interaction happens because there is a will, ability, time, and knowledge. When doing Pindapata, it is constrained by weather factors, security, distance, mental preparedness, envy, time, and intention. The impact of social interaction are emerging social order, social groups, social roles and social organizing. Benefits of Pindapata felt on individual aspects, social, spiritual, and financial.
\end{abstract}

Keywords: Pindapata, social interaction.

\section{Pendahuluan}

Sistem kemasyarakatan umat Buddha di Indonesia terbagi menjadi dua yaitu kelompok umat awam dan sangha. Orientasi hidup kedua kelompok ini berbeda, namun tetap memiliki hubungan sosial yang saling membutuhkan. Bhikkhu membutuhkan umat awam untuk memenuhi kebutuhan hidup, sedangkan umat awam membutuhkan bhikkhu untuk memenuhi kebutuhan batin. Salah satu cara bhikkhu untuk memenuhi kebutuhan hidup adalah dengan pindapata pada umat awam.

Pindapata merupakan kebiasaan luhur sejak zaman Buddha dengan cara berjalan kaki menuju pemukiman umat untuk menerima persembahan makanan dari umat. Bhikkhu bertemu langsung dengan umat yang 
mempersembahkan dana. Interaksi sosial bhikkhu dengan umat awam saat pindapata memiliki kekhasan yang tidak dapat disamakan dengan interaksi pada umumnya. Pada masa sekarang, pindapata berkembang dalam bentuk, waktu, tempat, motif, dan tujuannya. Perubahan dalam beberapa aspek tersebut, berimbas pada tatanan hidup masyarakat khususnya umat Buddha.

Berdasarkan latar belakang permasalahan di atas, peneliti tertarik untuk mendapatkan informasi yang jelas tentang dinamika interaksi sosial bhikkhu sangha dengan umat saat pindapata. Fokus penelitian ini adalah interaksi sosial bhikkhu Sangha Theravada Indonesia dengan umat awam saat pindapata di Jakarta dan Tangerang.

Istilah pindapata berasal kata pinda dan pata, dalam Visuddhi Magga diartikan sebagai menjatuhkan makanan ke dalam mangkuk yang dibawa bhikkhu (Ñānamoli, tanpa tahun: 60). Bhikkhu berjalan kaki sambil membawa mangkuk untuk menerima persembahan makanan dari umat yang dijatuhkan dalam mangkuk. Selain melalui pindapata, ada 7 jenis makanan yang diterima bhikkhu, yaitu: (1) Sanghabhatta adalah makanan yang diberikan kepada sangha; (2) udesabhatta adalah makanan yang didedikasikan kepada sangha; (3) nimantana adalah makanan yang diperoleh dari undangan; (4) salakhabhatta adalah makanan yang diberikan oleh orang-orang; (5) pakkhika adalah makanan yang diberikan sekali dalam dua minggu; 6) uposathika adalah makanan yang diberikan pada saat hari uposatha; (7) patipadika adalah makanan yang diberikan pada saat hari patipada (Vajirananavarorasa, 2000: 59).

Pindapata memberi manfaat bagi bhikkhu dan umat. Bhikkhu dapat mengukur kebajikan yang dimiliki. Bila dalam kehidupan sebelumnya banyak berdana, maka pada saat menjalani kehidupan kebhikkhuan akan memperoleh kemudahan menerima dana makanan, sering mendapatkan jubah, makanan, obat-obatan, penginapan, serta di mana pun bhikkhu tinggal, umat bersikap ramah dalam pemikiran, ucapan, dan perbuatan (Anguttara Nikaya Vol III part III chapter IV). Bagi umat, berdana kepada bhikkhu memiliki manfaat yang besar, karena bhikkhu hidup dengan cara suci, hidup yang terkendali, dan mengembangkan kewaspadaan (Anguttara Nikaya, Vol I, Part III chapter XVI), dan dipertegas dengan pernyataan bahwa persembahan yang luhur diberikan kepada orang yang terpelajar dan mahir (Anguttara Nikaya Vol 1 Part I Chapter IV).

Bhikkhu tidak dapat melakukan pindapata setiap saat. Bila salah waktu, akan menimbulkan bahaya dan kerugian bagi bhikkhu maupun umat awam. Jika dilakukan pada malam hari, bhikkhu tidak dapat melihat jalan yang dilalui dengan jelas, sehingga ada kemungkinan bhikkhu dapat terjerembab masuk tangki septik, jatuh ke selokan, berjalan di semak duri, atau berjalan di kandang sapi; bertemu dengan penjahat yang telah atau sedang merencanakan kejahatan (Latukikopama Sutta, Majjhima Nikaya). 
Hasil pindapata disimpan sesuai dengan aturan di vinaya. Ada empat jenis waktu penyimpanan makanan, yaitu setengah hari (yavakalika), satu hari (yamakalika), satu minggu (sattahakalika), dan tanpa ada batas waktu (yavajivika). Lama waktu penyimpanan hasil pindapata didasarkan pada daya tahan makanan atau minuman. Makanan dan minuman yang cepat basi paling lama boleh disimpan selama setengah hari. Makanan atau minuman yang tidak cepat basi paling lama disimpan dengan batas waktu tidak terbatas.

Pindapata tidak dapat disamakan dengan mengemis. Nyanatiloka meski memberikan istilah bhikkhu sebagai "biarawan pengemis", karena sekilas terlihat memohon bantuan, namun selanjutnya memberi penegasan bahwa bhikkhu tidak mengemis saat mengumpulkan persembahan dana makanan. Para bhikkhu berdiri diam (sejenak) di pintu umat (Nyanatiloka, 1980: 71 72). Bila umat tidak berdana, bhikkhu melanjutkan perjalanan.

Pindapata adalah bentuk kebudayaan Buddhis. Kebudayaan berasal dari bahasa Sansekerta yaitu buddhayah, bentuk jamak dari kata buddhi yang berarti budi atau akal (Soekanto, 2007: 150). Ralph Linton menyebut kebudayaan sebagai design for living yang artinya sebagai suatu garis-garis pokok dalam menciptakan pola kehidupan di masyarakat (Soekanto, 2007: 158). Menurut E. B. Taylor dalam Philip R. Haris dan Robert T. Moran (2006: 54), ruang lingkup kebudayaan sangat luas, agama merupakan sebagai bagian dari kebudayaan. Mengacu pada pendapat tersebut, pindapata merupakan kebudayaan keagamaan Buddha yang terkandung makna, nilai luhur, dan aturan-aturan sehingga tercipta pola aktivitas yang teratur. Pindapata sebagai kebudayaan yang bersifat dinamis. Soekanto (2007: 268) menjelaskan bahwa perubahan ada yang lambat atau cepat; kecil atau besar; dikehendaki atau tidak dikehendaki. Perubahan disebabkan faktor penduduk, penemuan teknologi-teknologi baru (Soekanto, 2007: 275 - 282).

Bhikkhu sangha dan umat terlibat interaksi saat pindapata. Ini merupakan bukti bahwa bhikkhu sangha dan umat keduanya memiliki sifat yang sama sebagai makhluk sosial. Memiliki kebutuhan yang sama untuk memenuhi kebutuhan hidup. Senada dengan teori Talcott Person dan Cohen, manusia berinteraksi untuk memenuhi kebutuhan demi mempertahankan kelangsungan hidup. Interaksi sosial dapat ditandai dengan adanya pelaku yang jumlahnya lebih dari satu; ada komunikasi antarpelaku dengan menggunakan simbol-simbol; ada dimensi waktu; ada tujuan-tujuan tertentu Setiadi (2011, 26-66). Hasil interaksi sosial berupa produk nilai-nilai dan norma-norma sebagai pedoman pergaulan serta terjadi pertukaran pesan atau melakukan komunikasi. Interaksi yang terus-menerus terjalin merupakan sebuah dinamika. Dinamika dalam konteks sosial menurut KBBI diartikan sebagai gerak masyarakat secara terus-menerus yang menimbulkan perubahan dalam tata hidup masyarakat yang bersangkutan. 
Interaksi sosial tidak akan berlangsung tanpa adanya kontak sosial dan komunikasi (Soekanto, 2007: 58). Kontak sosial dapat terjadi antara individu dan individu, individu dan kelompok, dan kelompok dengan kelompok. Sifat kontak sosial ada yang positif atau negatif. Komunikasi sebagai unsur penting dalam kontak sosial berhubungan dengan perilaku manusia dan kepuasan terhadap terpenuhinya kebutuhan berinteraksi, mengomunikasikan ide, pemikiran atau keinginan kepada orang lain (Mulyana dan Jalaluddin Rakhmat, 2006: 12 - 13). Ada beberapa karakteristik dari komunikasi yaitu komunikasi terus berlangsung dan selalu berubah; melibatkan dua pihak atau lebih; tidak dapat dibalik (irreversible) artinya sekali pesan disampaikan kepada orang lain dan pesan tersebut diterima maka pesan tersebut tidak dapat ditarik kembali; berlangsung dalam konteks fisik dan sosial (Mulyana dan Jalaluddin Rakhmat, 2006: 17). Setiadi (2011: 95) menyatakan bahwa kontak sosial menghasilkan keteraturan sosial dan ketidakteraturan sosial; kelompok-kelompok sosial; kelas sosial; peranan sosial; organisasi sosial.

\section{Metode}

Penelitian dengan judul "Budaya Pindapata: Dinamika Interaksi Sosial Bhikkhu Sangha dengan Umat Awam" merupakan jenis penelitian deskriptif kualitatif. Penelitian ini mengarah pada pemberian interpretasi terhadap makna suatu data (Sugiyono, 2013: 228). Objek penelitian adalah budaya pindapata dan interaksi sosial. Subjek penelitian ini adalah bhikkhu atau sangha, romo atau ramani, dan upasaka atau upasika. Penelitian dilaksanakan di wilayah Tangerang dan Jakarta terutama dimulai pada bulan Februari sampai dengan Juni 2016.

Teknik dan instrumen pengumpulan data melalui observasi, wawancara, dan dokumentasi. Untuk menguji keabsahan data penelitian dilakukan dengan triangulasi, uji kredibilitas, dependabilitas, konfirmabilitas, dan transferbilitas hasil penelitian. Analisis data menggunakan teknik Miles dan Huberman.

\section{Hasil dan Pembahasan}

Berdasarkan hasil pengamatan, wawancara, dan dokumentasi, pindapata yang diadakan oleh bhikkhu Sangha Theravada Indonesia di wilayah Tangerang dan Jakarta telah lama berlangsung. Pindapata dilakukan pada harihari tertentu, seperti untuk menyambut hari Waisak. Pindapata menjadi ajang interaksi antara bhikkhu sangha dengan umat. Para bhikkhu bertemu langsung dengan umat, terlibat kontak dan menjalin komunikasi dengan maksud dan tujuan tertentu. Bhikkhu berpedoman pada tradisi, aturan dalam vinaya dan pada situasi-situasi tertentu membuat kesepakatan atas dasar pertimbangan manfaat yang lebih besar bagi umat. Sementara itu, umat 
menjalin interaksi dengan bhikkhu berpedoman pada sikap bakti dan hormat kepada bhikkhu.

Pindapata mengalami perkembangan pada aspek pemahaman dan animo masyarakat. Pada mulanya banyak umat yang belum memahami pindapata, belum mengerti cara berbuat baik saat ada pindapata. Kini umat telah mengerti cara berpartisipasi dalam pindapata. Pelaksanaan pindapata mengalami peningkatan frekuensi seiring dengan respon dari umat. Bhikkhu pun meluangkan waktu untuk mengikuti program pindapata khususnya untuk bakti sosial.

Pindapata merupakan bagian dari program sangha. Ada berbagai program sangha di dalamnya terdapat kegiatan pindapata, tidak dijadikan program. Bhikkhu sangha juga mengadakan pindapata manakala menerima permohonan dari umat. Pindapata menjadi sarana menunjukkan eksistensi sangha.

1. Pindapata sebagai wujud kebudayaan Buddhis

Pindapata diselenggarakan mengacu pada tradisi yang sudah lama berlangsung sejak zaman Buddha. Buddha melakukan pindapata dengan mengadopsi cara pertapa dalam mendapatkan makananan. Namun pindapata yang dilakukan oleh Buddha Gotama dan sangha memiliki cara yang khas mengacu pada aturan yang kemudian dikenal dengan vinaya, diantaranya waktu pindapata, cara mengenakan jubah saat pindapata, sikap bhikkhu saat pindapata. Pindapata yang dilakukan oleh Buddha dan murid-murid beliau memiliki ciri khas yang tidak dapat disamakan dengan pertapa dari aliran lain.

Ide penyelenggaraan pindapata di Jakarta dan Tangerang muncul karena banyak hal diantaranya untuk melestarikan tradisi yang sudah ada sejak zaman Buddha Gotama; untuk memenuhi kebutuhan makanan dan minuman; untuk memberikan kesempatan kepada umat melakukan kebaikan; serta sarana mengumpulkan dana sosial. Pelaksanaan pindapata saat ini untuk mengenalkan kepada umat Buddha dan masyarakat tentang bentuk penghidupan para bhikkhu sesuai kebiasan Buddha dan murid-murid beliau. Bhikkhu mendapatkan makanan yang dipersembahkan umat dan di sisi lain umat mendapatkan berkah atas dana yang diberikan pada bhikkhu. Selain itu, hasil pindapata dalam jumlah yang banyak dapat digunakan untuk membantu pihak yang membutuhkan seperti panti asuhan, panti jompo, dan masyarakat yang kurang mampu.

Norma-norma yang menjadi pedoman bagi bhikkhu sangha melakukan pindapata mengacu pada sumber tekstual yaitu patimokha yang terdapat dalam vinaya pitaka (aturan hidup yang wajib dipatuhi oleh para bhikkhu). Selain aturan dalam patimokha, bhikkhu sangha juga mempertimbangkan faktor kontekstual dan situasional dalam memutuskan aturan yang diterapkan. Oleh karena itu, kadang bhikkhu sangha membuat aturan atas dasar kesepatan 
sangha yang tidak sesuai dengan vinaya. Seperti menerima dana melebih batas maksimal dana yang boleh diterima agar semua umat dapat berdana.

Pada awalnya penyelenggaraan pindapata sebagai sarana untuk mengenalkan tradisi. Seiring dengan perkembangan agama Buddha, pindapata menjadi lebih sering diselenggarakan. Pindapata menjadi sarana pembiasaan berbuat baik. Umat menjadi terbiasa berdana kepada bhikkhu yang pindapata. Ini dapat dilihat dari animo umat yang berdana pada bhikkhu yang pindapata terus bertambah. Pindapata juga menjadi sarana meningkatkan kegairahan umat maupun para bhikkhu melakukan kebaikan. Bhikkhu dan umat merasa bahagia, dan bangga memiliki kesempatan berpartisipasi dalam kegiatan pindapata.

Bhikkhu menunjukkan nilai-nilai kesederhanaan dan kehormatan yang menjadi praktik hidup sehari-hari saat pindapata. Bhikkhu berjalan kaki tanpa menggunakan alas kaki, mengenakan satu set jubah dan membawa mangkuk yang dilengkapi tutup. Jubah yang dikenakan bhikkhu merupakan lembaran kain yang digulung dengan teknik tertentu sehingga membentuk rupa seperti pakaian. Sebuah praktik hidup yang kontras dengan masyarakat pada umumnya yang cenderung konsumtif. Bhikkhu menunjukkan sikap terhormat dengan cara mengenakan jubah secara rapi dan bersih, berjalan penuh perhatian, menerima persembahan dengan kehati-hatian, dan tenang selama pindapata.

Dari sisi lain, sikap bakti dan hormat ditujukan umat pada bhikkhu. Berdana dengan penuh semangat, antusias, dan bahagia. Bersikap anjali saat menunggu kedatangan bhikkhu, membungkukkan badan atau sambil berlutut saat memasukkan dana makanan ke dalam mangkuk, serta anjali bahkan bernamakara setelah mempersembahkan dana kepada para bhikkhu yang pindapata. Umat menghormati bhikkhu didasari pada kesadaran bahwa para bhikkhu menerapkan sila dengan jumlah lebih banyak. Setelah melakukan kebaikan, umat berdoa dengan harapan mendapatkan kelancaran, kesejahteraan, serta sanak saudara yang telah meninggal turut berbahagia.

Bhikkhu yang pindapata menerima semua persembahan umat dengan baik. Tidak membedakan pemberi atau umat antara umat laki-laki maupun perempuan, tua atau muda, miskin atau kaya. Semua persembahan diterima langsung ke dalam pata atau mangkuk bhikkhu. Bahkan bhikkhu tidak melihat umat yang berdana, tetapi fokus mengamati mangkuk yang dibawa.

Setelah menerima dana, bhikkhu memberi respon dengan tersenyum, mengucapkan anumodana (turut berbahagia dengan kebaikan yang dilakukan umat), ayu vanno sukham balam (semoga mendapat berkah usia panjang, paras rupawan, bahagia, dan kekuatan). Bila pindapata dilakukan perorangan, bhikkhu memiliki kesempatan mengucapkan kalimat pemberkahan dalam bahasa pali "Yatha varivaha pura paripurenti sagaram. Evameva ito dinnam petanam 
upakappati. Icchitam pattitam tumham khippameva samijjhatu. Sabbe purentu sankappa. Cando pannaraso yatha. Mani jotiraso yatha".

Pindapata merupakan salah satu cara menggali potensi kebaikan yang dimiliki umat khususnya kemampuan berdana. Pindapata mengondisikan umat menumbuhkan kedermawanan. Bhikkhu atau sangha sebagai pihak penerima mempersiapkan diri dengan baik agar pantas menerima persembahan umat. Membiasakan hal-hal yang sesuai dengan aturan patimokha dalam kehidupan sehari-hari, diantaranya cara mengenakan jubah dan cara membawa pata atau mangkuk. Persepsi umat yang positif pada bhikkhu ditunjukkan pada respon umat pada pindapata. Umat senang, bangga, dan antusias berdana pada bhikkhu yang pindapata.

Bila pindapata dilakukan oleh sangha atau lebih dari lima orang bhikkhu, maka para bhikkhu membuat barisan "one line". Para bhikkhu berjalan satu per satu pada rute yang telah ditentukan. Sebelum mulai pindapata sangha terlebih dahulu menentukan susunan barisan mulai bhikkhu yang berjalan terdepan sampai paling belakang. Susunan barisan bila mengacu pada vinaya dimulai dari bhikkhu yang memiliki usia vassa paling banyak, disusul dengan bhikkhu yang memiliki usia vassa lebih sedikit, demikian seterusnya sampai paling belakang. Namun susunan barisan bhikkhu dapat diubah sesuai dengan kesepakatan sangha.

Bhikkhu dan umat saat pindapata menempatkan posisi masing-masing. Para bhikkhu berada di sebelah kanan dari umat yang mempersembahkan dana. Bhikkhu berjalan secara tenang dan teratur dan umat yang berdana berdiri atau bersimpuh berjejer sepanjang jalan. Bila jumlah umat yang mempersembahkan dana melebihi kapasitas jalur pindapata, maka umat berdiri di belakang umat yang lain. Pada saat mempersembahkan dana, dilakukan secara bergantian ke dalam mangkuk bhikkhu. Satu per satu umat memasukkan dana ke dalam mangkuk bhikkhu.

Ketika mangkuk bhikkhu telah berisi penuh, tapi umat yang akan berdana masih ada, bhikkhu mempersilakan kapiyakaraka untuk mengambil dana yang ada di dalam mangkuk untuk dikumpulkan di penampungan yang biasanya berupa karung atau plastik besar. Dengan cara demikian, bhikkhu memberi kesempatan berdana kepada seluruh umat.

Pindapata memerlukan sarana dan prasarana penunjang. Para bhikkhu menggunakan seperangkat jubah dan membawa mangkuk atau pata. Cara mengenakan disesuaikan dengan tempat pelaksanaan pindapata. Bhikkhu mengenakan jubah dengan pundak kanan terbuka bila pindapata dilakukan di dalam lingkungan vihara, sebaliknya jika di lingkungan luar vihara atau di area umum, bhikkhu mengenakan jubah tertutup yaitu dengan kedua pundak tertutup.

Tiap bhikkhu membawa satu pata yang dilengkapi dengan penutup pata. pata berfungsi untuk menerima persembahan dana dari umat. Pata yang 
dibawa bhikkhu umumnya terbuat dari aluminium. Bhikkhu membuka dan menutup pata dengan penuh kehati-hatian. Bhikkhu memegang pata dengan menggunakan tangan kiri dan menempatkan di depan perut, sedangkan tutup pata dipegang dengan tangan kanan. Selain dipegang, pata dapat diletakkan pada tas yang dilengkapi dengan tali yang dikalungkan di leher bhikkhu.

Sarana penunjang lain yang dibutuhkan dalam kegiatan pindapata antara lain tempat penampungan dan alat transportasi, serta pengeras suara. Bila dana yang diterima melebihi kapasitas mangkuk, maka dana yang di dalam mangkuk diambil dan ditempatkan di penampungaan. Kendaraan berguna untuk mengantarkan bhikkhu dari vihara ke lokasi pindapata jika jauh dari vihara. Pengeras suara digunakan panitia untuk mengarahkan umat agar berada di posisi benar serta dapat tertib dalam mengikuti kegiatan pindapata.

\section{Bentuk interaksi sosial pada saat pindapata}

Bhikkhu bertemu langsung dengan umat yang mempersembahkan dana. Pindapata dapat dilakukan oleh seorang bhikkhu kepada sejumlah umat, sekelompok bhikkhu atau sangha kepada masyarakat, sangha kepada umat. Bila ada umat yang mau berdana, bhikkhu berhenti sejenak dengan posisi berdiri lalu membuka tutup mangkuk secara hati-hati untuk memberi kesempatan umat memasukkan dana ke dalam mangkuk, setelah menerima persembahan dari umat, mangkuk ditutup dengan hati-hati lalu bhikkhu meneruskan perjalanan. Ketika mangkuk penuh namun masih banyak umat yang akan berdana, bhikkhu mempersilakan kapiyakaraka mengambil dana yang ada di dalam mangkuk untuk dikumpulkan sementara dengan hasil persembahan dana yang lainnya.

Komunikasi yang terjadi selama kegiatan pindapata adalah lisan atau verbal dan simbolik. Bhikkhu diam saat berjalan, ketika bhikkhu selesai menerima persembahan dari umat lalu bhikkhu mengucapkan kata-kata atau kalimat singkat seperti anumodana, ayu vanno sukham balam, semoga pekerjaan lancar dan hidup sejahtera. Bila memungkinkan untuk mengucapkan kalimat panjang, maka bhikkhu akan mengucapkan kalimat pemberkahan "Yatha varivaha pura paripurenti sagaram. Evameva ito dinnam petanam upakappati. Icchitam pattitam tumham khippameva samijhatu. Sabbe purentu sankappa. Cando pannaraso yatha. Mani jotiraso yatha". Ada juga bhikkhu yang hanya tersenyum ketika menerima persembahan makanan dari umat. Umat yang mendengarkan kalimat pemberkahan dari bhikkhu akan bersikap anjali atau namakara lalu mengucapkan sadhu sebanyak tiga kali yang artinya semoga demikian adanya.

Bhikkhu menjaga perhatian dengan pandangan mata tertuju ke mangkuk selama proses pindapata. Berjalan tenang dan penuh kesadaran melewati rute-rute yang telah ditentukan. Tidak menengok ke kanan atau ke kiri untuk melihat lingkungan sekitar. Bila pindapata dilakukan berkelompok, 
maka bhikkhu berjalan tertib di barisan yang telah ditentukan, tidak saling mendahului.

Setelah bhikkhu menerima persembahan dana dari umat, lalu melanjutkan perjalanan sesuai dengan rute pindapata. Bila dalam perjalanan pindapata tidak ada umat yang akan berdana, maka bhikkhu berjalan terus sampai bhikkhu tersebut bertemu dengan umat yang akan berdana. Saat berjalan, bhikkhu menutup mangkuk dan akan membuka ketika ada umat yang akan memasukkan makanan ke dalam makanan. Setelah dana dimasukkan ke dalam mangkuk, mangkuk akan ditutup kembali oleh bhikkhu.

Bentuk interkasi dari sisi umat awam, pada saat menunggu kedatangan bhikkhu, umat menunggu berkomunikasi dengan orang-orang yang ada di sekitar. Namun ketika akan berdana, umat diam hingga dana selesai dilakukan. Umat tidak menyapa bhikkhu atau mengajak berbincang-bincang. Selama kegiatan pindapata, fokus utama interaksi umat pada bhikkhu adalah mempersembahkan dana.

Pada umumnya umat tidak mengenakan alas kaki berdiri di sebelah kiri jalur pindapata untuk menghormati bhikkhu. Ada sebagian umat yang tetap memakai sepatu atau sandal. Melepas alas kaki atau tidak melepas alas kaki merupakan hak bagi tiap umat. Tidak ada keharusan dari pihak bhikkhu sangha. Atas dasar kesadaran diri, umat akan melepas alas kaki sebagai simbol menghormati bhikkhu. Lalu bersimpuh di tanah bila berada di tempat yang memungkinkan untuk mempersembahkan dana dengan dua tangan atau satu tangan, lalu beranjali atau bernamakara.

Kegiatan pindapata untuk bakti sosial dikoordinir oleh kepanitiaan yang merupakan gabungan antara umat awam dan bhikkhu demi memastikan kelancaran acara. Rute pindapata ditentukan, waktu pindapata sudah ditetapkan jauh sebelum hari pelaksanaan dan diumumkan kepada umat, diatur posisi barisan bhikkhu, dan hasil pindapata sepenuhnya digunakan untuk kegiatan sosial.

3. Tujuan interaksi sosial bhikkhu dengan umat saat pindapata

Esensi dari tujuan pelaksanaan pindapata adalah untuk memenuhi kebutuhan pokok bhikkhu khususnya makanann dan minuman. Bhikkhu pergi dengan berjalan kaki sambil membawa mangkuk untuk menerima makanan dan minuman yang dipersembahkan umat. Dari sisi umat, kegiatan pindapata dijadikan sarana untuk memenuhi kebutuhan mendapatkan berkah. Pada umumnya umat Buddha yang masih mengharapkan berkah antara lain hidup sejahtera, rejeki lancar, tampang rupawan, panjang umur, leluhur hidup bahagia, dan bila meninggal terlahir di alam surga. Sesuai dengan keyakinan umat Buddha, berkah akan diperoleh bila telah melakukan perbuatan baik. Berdana kepada bhikkhu sangat baik karena bhikkhu menjalankan kehidupan yang suci. 
Pindapata dari segi sosial atau kemanusiaan bertujuan untuk membantu pihak-pihak lain. Pindapata menjadi sarana untuk menggalang dana untuk disalurkan ke pihak-pihak yang membutuhkan bantuan, seperti panti asuhan, panti jompo atau masyarakat kurang mampu. Selain itu, pindapata bertujuan untuk dibagikan kepada umat yang datang ke vihara. Setelah bhikkhu mengambil hasil pindapata sesuai kebutuhan, selebihnya diserahkan kembali kepada umat untuk dinikmati secara bersama-sama. Pindapata juga digunakan untuk kegiatan sosial di dalam komunitas sangha, misalnya hasil pindapata disalurkan ke tempat penyelenggaraan pendidikan bagi samanera dan atthasilani.

4. Faktor-faktor yang menyebabkan terjadinya interaksi sosial saat pindapata

Kemauan atau niat berbuat baik diantara bhikkhu sangha dengan umat melalui kegiatan pindapata menjadi penyebab internal terjadinya interaksi antara bhikkhu dengan umat. Bhikkhu berniat membantu umat dengan cara memberi kesempatan umat berbuat baik kepada bhikkhu akan melakukan pindapata. Umat yang memiliki niat berbuat baik akan berupaya mewujudkan keinginan berbuat baik dengan cara pindapata. Bhikkhu yang mau mengukur kamma baik juga dapat melakukan pindapata. Bila memiliki kamma baik bhikkhu, maka pindapata akan memperoleh banyak sokongan dari umat, sebaliknya jika kurang, bhikkhu bisa kesulitan memperoleh dana dari pindapata.

Faktor kedua adalah kemampuan. Kemampuan bhikkhu melakukan pindapata diantaranya dikarenakan memiliki mangkuk. Tanpa adanya mangkuk, bhikkhu tidak bisa melakukan pindapata. Mangkuk menjadi perlengkapan vital yang diperlukan dalam pindapata bagi. Dari segi umat, kemampuan berdana pada saat ada pindapata ditandai dengan memiliki barang-barang yang didanakan. Kemampuan yang lain adalah dalam bentuk kesehatan. Bhikkhu dapat berpindapata untuk menerima persembahan dari umat apabila kondisi tubuh sehat, mampu berjalan sejauh rute pindapata, mampu menerima persembahan dari umat. Umat dapat pergi ke lokasi pindapata dan mempersembahkan dana dengan cara yang baik kepada para bhikkhu.

Faktor yang ketiga adalah waktu. Bhikkhu dan umat membutuhkan waktu yang tepat untuk berinteraksi pada saat pindapata. Waktu pindapata umumnya dilakukan pada pagi hari atau di hari libur. Pindapata yang dilakukan hanya di waktu-waktu tertentu memungkinkan para bhikkhu untuk mengikuti kegiatan ini di sela-sela kegiatan bhikkhu yang lainnya. Agar dapat berinteraksi, baik bhikkhu maupun umat harus meluangkan waktu diantara kegiatan yang lain demi berpartisipasi dalam kegiatan. 
Faktor lain yang menyebabkan interaksi bhikkhu dengan umat saat pindapata adalah ilmu. Ilmu berupa pengertian terhadap arti, manfaat, cara berpindapata. Berdasarkan pengertian terhadap pindapata dan manfaat yang diperoleh bhikkhu maupun umat, bhikkhu maupun umat memutuskan berpartisipasi dalam kegiatan pindapata. Bhikkhu yang memahami pindapata sebagai tradisi sejak jaman Buddha berusaha untuk melestarikan tradisi. Umat yang memahami arti dan manfaat berdana pada bhikkhu yang pindapata. Ilmu berupa keterampilan bhikkhu dan umat ditunjukan dengan cara mematuhi aturan-aturan dalam pelaksanaan pindapata sehingga pelaksaaan pindapata lancar. Bhikkhu menerapkan aturan-aturan sesuai vinaya meskipun pada situasi tertentu mengubah aturan demi manfaat bagi umat yang lebih besar, sedangkan umat mempraktikkan sikap hormat kepada bhikkhu.

5. Kendala-kendala dalam interaksi sosial pada saat pindapata

Secara umum, kendala-kendala yang dalam penyelenggaraan pindapata dapat disebabkan oleh dua faktor yaitu faktor eksternal dan internal. Faktor eksternal antara lain: terik matahari, hujan deras, keamanan, jarak yang jauh. Kendala dari internal berupa ketidaksiapan mental, irihati, kesibukan, keyakinan bahwa kamma baik tidak mendukung, dan niat yang lemah.

Cuaca yang cerah dengan sinar matahari yang terik membuat udara menjadi panas. Bila kondisi tubuh bhikkhu kurang fit sedangkan rute pindapata jauh, maka pindapata dapat terkendala. Bhikkhu tidak mampu menyelesaikan pindapata sesuai dengan rute yang akan ditempuh. Untuk mengantisipasi kejadian seperti ini, bila pindapata diselenggarakan oleh sebuah kepanitiaan, maka dapat diantisipasi dengan menyediakan kendaraan penjemput. Panitia juga dapat mempersiapkan payung untuk mengantisipasi turun hujan. Kendala keamanan diatasi dengan berkoordinasi dengan pihak keamaman seperti polisi dan TNI untuk membantu mengamankan pelaksanaan pindapata.

Dari segi internal, kendala-kendala di atas dapat dialami oleh bhikkhu maupun umat awam. Seperti ketidaksiapan mental merupakan kendala yang bisa dialami oleh bhikkhu mudah, merasa canggung karena menerima persembahan dana dari orangtua atau merasa tidak nyaman dengan jenis atau jumlah dana yang diterima dibandingkan dengan bhikkhu lain. Dengan menyadari bahwa menjadi bhikkhu merupakan latihan hidup, kendala ini secara bertahap diatasi. Kesibukan kerja, sekolah merupakan kendala yang dialami umat. Manajemen waktu merupakan solusi yang tepat bagi perumah tangga untuk mengatasi kendala ini. Niat berdana yang lemah atau menganggap bahwa belum mempunyai kamma yang cukup untuk berdana adalah kendala internal lainnya yang dapat diatasi dengan memahami arti dan manfaat berdana pada bhikkhu. 
6. Dampak interaksi sosial antara bhikkhu sangha dengan umat awam saat pindapata

Ada beberapa dampak langsung yang timbul dari budaya pindapata. Dampak yang pertama adalah terjadi keteraturan sosial saat pindapata. Bhikkhu maupun umat yang berdana menjaga sikap dan perilaku sehingga tercipta kondisi yang tertib. Bila pindapata dilakukan oleh sangha, maka sebelum memulai pindapata sangha membentuk satu baris. Bhikkhu yang senior atau yang paling banyak vassa berada diurutan barisan terdepan atau sebaliknya. Selama pindapata bhikkhu berjalan sesuai dengan rute yang telah ditentukan dan berjalan sesuai urutan serta tidak saling mendahului. Keteraturan umat tampak saat akan berdana dengan cara menempatkan diri di sebelah kiri rute pindapata. Menunggu kedatangan bhikkhu di tempat yang telah ditentukan. Umat mempersembahkan dana kepada bhikkhu yang berdiri di depan umat tanpa memilih antara satu bhikkhu atau bhikkhu lain secara bergantian satu persatu memasukan dana ke dalam mangkuk bhikkhu hingga semua umat mendapatkan kesempatan berdana.

Dampak kedua adalah timbul kelompok sosial. Ada dua kelompok besar yaitu kelompok bhikkhu sangha dan kelompok umat awam. Para bhikkhu berkumpul sebelum memulai pindapata untuk memutuskan beberapa hal, salah satunya adalah kesepakatan mengenai format urutan barisan pindapata. Setelah kegiatan pindapata selesai, para bhikkhu akan kembali ke vihara masing-masing. Kelompok umat mulai berkumpul sejak menunggu kedatangan bhikkhu yang pindapata sampai tahap menyerahkan dana dengan berdiri berjejer di sebelah kiri sepanjang rute pindapata. Bila jumlah umat yang berdana sangat banyak, maka umat berdiri di barisan belakang umat yang berdiri di barisan paling depan. Setelah selesai menyerahkan dana, umat meninggalkan kelompok namun tetap menjaga ketertiban.

Dampak langsung ketiga adalah pengorganisasian. Pindapata merupakan kegiatan yang melibatkan banyak pihak. Ada kelompok bhikkhu, kelompok umat, dan kelompok panitia, relawan atau petugas keamanan. Agar setiap kelompok dapat berpartisipasi sesuai dengan peran, maka dibutuhkan pengorganisasian dan pengarahan. Memastikan semua pihak yang terlibat memahami peran dan tanggung jawab dengan baik. Pelaksanaan pindapata yang terencana memudahkan bhikkhu sangha, panitia, dan umat. Selesai pindapata, hasilnya dikelompokkan sesuai dengan jenis dan daya tahan makanan yang selanjutnya didistribusikan sesuai dengan tujuan pindapata. Dampak keempat dari interaksi sosial adalah peran sosial. Bhikkhu sangha dan umat memiliki peran penting dalam kegiatan pindapata.

\section{Peran bhikkhu dalam kegiatan pindapata}

Bhikkhu sangha menerima persembahan dana dari umat. Semua persembahan yang diberikan oleh umat diterima dengan menggunakan mangkuk atau pata, kecuali jika ada umat yang mempersembahkan dana 
dalam bentuk uang tunai maupun uang dalam bentuk lainnya maka persembahan tersebut diterima langsung oleh kapiyakaraka. Setelah menerima persembahan umat, bhikkhu memberikan pemberkahan dengan mengucapkan kata-kata seperti anumodana, ayu vanno sukham balam. Berkah yang dimaksud adalah doa dan harapan bahwa dengan perbuatan baik yang telah dilakukan umat berbuah kebahagiaan. Pada intinya bhikkhu turut berbahagia dengan kebaikan yang telah dilakukan oleh umat dan mendoakan semoga berkat kebaikan tersebut umat memperoleh berkah kebahagiaan, paras rupawan, kesejahteraan, dan kekuatan atau kesehatan.

Bhikkhu atau sangha adalah komunitas non-perumahtangga yang telah memiliki komitmen untuk menjalankan kehidupan suci secara ikhlas tanpa ada paksaan dari pihak manapun. Bhikkhu juga menjalankan kehidupan yang sederhana. Pola hidup bhikkhu juga teratur, seperti makan sehari dua kali yaitu pagi dan siang hari. Penghormatan kepada sangha merupakan bentuk apresiasi dari penghidupan para bhikkhu sangha.

\section{Peran umat dalam kegiatan pindapata}

Umat mempersembahkan dana dengan berbagai cara antara lain dengan menggunakan dua tangan atau satu tangan sesuai dengan kondisi tempat berdana. Dana yang dipersembahkan pada umumnya adalah makanan siap santap atau makanan kering dan minuman botol atau kaleng. Umat juga mempersembahkan barang-barang untuk kebutuhan bhikkhu yang lain, seperti uang.

Umat menjadi pihak yang menerima pemberkahan setelah berdana pada bhikkhu. Pemberkahan dilakukan bhikkhu dengan mendoakan untuk kebahagiaan dan kesejahteraan umat. Kebahagiaan dan kesejahteraan hidup merupakan hasil dari perbuatan-perbuatan baik yang dilakukan yaitu berdana.

Pada saat ada pindapata, umat memberikan penghormatan yang layak kepada para bhikkhu. Ada beberapa sikap menghormat yang dilakukan umat kepada bhikkhu antara lain dengan berdiri di posisi yang lebih rendah dari pada bhikkhu, memberikan persembahan dengan dua tangan, bersikap anjali sambil berdiri atau bersimpuh sebelum dan setelah mempersembahkan dana, bernamaskara setelah mempersembahkan dana.

Umat juga dapat berperan menjadi kapiyakaraka yang bertugas mengambil dana dari dalam mangkuk bhikkhu setelah dipersilakan bhikkhu, mengumpulkan dana tersebut ke dalam karung atau tempat penampungan sementara, menyortir dana sesuai dengan jenis atau kelompok makanan yang diterima, setelah dana-dana tersebut telah rapi, maka dipersembahkan kembali kepada bhikkhu untuk digunakan sesuai tujuan pindapata. 


\section{Manfaat Pindapata}

Pindapata menimbulkan kekuatan batin yang tidak tampak. Orangorang yang terlibat dalam kegiatan pindapata hidup gembira, bahagia, tenteram, damai berkat kekuatan kebaikan. Timbul keyakinan akan kebahagiaan yang diperoleh akibat berbuat kebaikan yang dilakukan saat pindapata. Manfaat lain adalah melatih kesabaran, umat bersabar dalam mengikuti semua proses kegiatan pindapata mulai dari menunggu kedatangan bhikkhu, ketika berdesak-desakan, hingga saat menyerahkan dana kepada bhikkhu. Bhikkhu pun bersabar dengan memberi kesempatan pada umat yang ingin berdana. Manfaat terakhir yang dirasakan umat adalah batin menjadi damai setelah mempersembahkan dana kepada bhikkhu.

Pindapata secara sosial ini menjadi ajang interaksi, ajang pertemuan antara bhikkhu dan umat. Ada temu muka, temu wicara, temu karya. Bhikkhu dan umat bertemu langsung, terlibat komunikasi secara simbolik. Semua pihak yang terlibat dalam kegiatan pindapata menyatukan pikiran, ucapan dan perbuatan ke arah kebaikan untuk mensukseskan acara. Pindapata yang terselenggara dengan lancar akan menimbulkan kebanggaan pada umat Buddha.

Secara individual, para bhikkhu bisa mengukur kekuatan kebajikan pribadi. Bila kamma baik yang dimiliki bhikkhu banyak, maka pada saat pindapata umat akan antusias mendukung, mempersembahkan barang-barang dengan perasaan riang gembira, antusias, bahkan umat mengucapkan terima kasih. Melalui pindapata, kebutuhan-kebutuhan pokok bhikkhu seperti makanan dan minuman terpenuhi, sehingga secara tidak langsung akan menjaga kelangsungan hidup bhikkhu. Umat secara pribadi bisa mengukur kualitas batin dalam berdana, didasarkan pada rasa antusias, tulus dan ikhlas, tidak minta dibalas.

Secara finansial, umat akan menabung atau menyisihkan sebagian penghasilan untuk dialokasikan kepada kegiatan pindapata tahun selanjutnya. Menganggarkan untuk membeli barang-barang yang yang akan didanakan kepada bhikkhu sangha saat pindapata. Umat memanfaatkan harta yang dimiliki untuk melakukan amal. Pada efek yang lebih luas, pindapata akan menyebabkan perputaran uang di masyarakat. Umat berbelanja barangbarang di toko-toko dalam jumlah yang lebih dari kebutuhan sehari-hari.

\section{Kesimpulan}

Dari hasil analisis data dan pembahasan, dapat disimpulkan bahwa pindapata merupakan kebudayaan buddhis dalam wujud abstrak, aktivitas sosial dan material. Bentuk interaksi sosial saat pindapata melibatkan bhikkhu dengan umat untuk tujuan pemenuhan kebutuhan pokok dan sosial. Interaksi sosial terjadi karena ada kemauan, kemampuan, waktu, dan ilmu. Pindapata dapat terkendala oleh beberapa faktor seperti cuaca, keamanan, jarak, kesiapan mental, irihati, waktu, dan niat. Dampak dari interaksi sosial 
antara lain muncuk keteraturan sosial, kelompok sosial, pengorganisasian sosial dan peranan sosial. Manfaat dari pindapata dirasakan pada aspek individu, sosial, spiritual, dan finansial.

Berdasarkan hasil penelitian, saran peneliti adalah: Sangha meningkatkan intensitas kegiatan dan menambah lokasi kegiatan pindapata; Majelis mendukung kegiatan pindapata untuk kebutuhan pokok bhikkhu maupun untuk tujuan bakti sosial; lembaga pendidikan mengundang bhikkhu sangha untuk melaksanakan pindapata sebagai bagian dari pembelajaran untuk siswa; Vihara menjadikan pindapata sebagai kegiatan rutin tidak hanya untuk menyambut hari-hari raya agama Buddha tetapi di waktu-waktu lain; Masyarakat khususnya umat Buddha lebih antusias berpartisipasi dalam kegiatan pindapata karena memberi manfaat buat pribadi, bhikkhu, sangha, dan masyarakat luas,

\section{Daftar Pustaka}

Anguttara Nikaya: The Book of The Gradual Sayings. Vol. I. 2008. Tr. F.L. Woodward. Oxford: The Pali Text Society.

Anguttara Nikaya: The Book of The Gradual Sayings. Vol. II. 2008. Tr. F.L. Woodward. Oxford: The Pali Text Society.

Anguttara Nikaya: The Book of The Gradual Sayings. Vol. III. 2008. Tr. F.L. Woodward. Oxford: The Pali Text Society.

Buddhaghosa, Bhadantacariya. Tanpa tahun. Visuddhi Magga: The Path of Purification. Translated from the Pali by Bhikkhu Nanamoli. Taiwan: The Corporate Bpdy of the Buddha Education Foundation.

Digha Nikaya, Brahmajala Sutta, Sutta 1: Discourse on the Net of Perfect Wisdom, Burma Pitaka Association edition;

Farganis, James. 2014. Readings in Social Theory: The Classic Tradition to Post-Modernism. Sevent Edition. New York: McGraw-Hill Education.

Mulyana, Deddy dan Jalaluddin Rakhmat. Komunikasi Antarbudaya: Panduan Berkomunikasi dengan Orang-Orang Berbeda Budaya. 2006. Bandung: Remaja Rosdakarya

Nyanatiloka. 1980. Buddhist Dictionary: Manual of Buddhis Term and Doctrines, Fourth Revise Edition. Kandy : Buddhist Publication Society.

Soekanto, Soerjono. 2007. Sosiologi Suatu Pengantar. Jakarta: PT Rajagrafindo Persada.

Sugiyono. 2013. Cara Mudah Menyusun Skripsi, Tesis, dan Desertasi. Bandung: Alfabeta

Tim Penyusun. 2008. Kamus Besar Bahasa Indonesia Edisi Keempat. Jakarta: Departemen Pendidikan Nasional.

Vajirananavarorasa, Somdet Phra Maha Samana Chao Krom Phraya. 2000. The Entrance To The Vinaya. Vinayamukha Vol. II. Bangkok: Mahamakut Rajavidyalaya Press. 
Vajirananavarorasa, Somdet Phra Maha Samana Chao Krom Phraya. 2000. The Entrance To The Vinaya. Vinayamukha Vol. III. Bangkok: Mahamakut Rajavidyalaya Press.

Walshe, Maurice. 2009. The Long Discources of The Buddha A Translation of The Digha Nikaya (Khotbah-khotbah Panjang Sang Buddha: Digha Nikaya). Diterjemahkan oleh Team Giri Mangala Publicatioan dan Team DhammaCitta Press. Tanpa Kota: DhammaCitta 